\title{
馬鈴薯菌アミラーゼによる澱粉の一分解成績體 (四糖體)の構造に就いて(第四報)
}

\author{
秋 谷七 郎 \\ (束京藻學專門學校女子部) \\ (炤和 13 年 2 月 3 日受理)
}

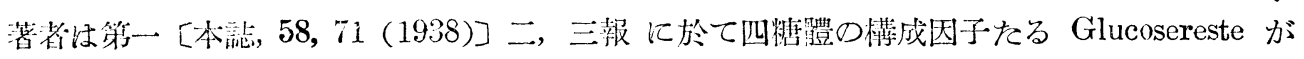
(2:3:6) 亿遊㒕 OH一基があり且つ Glucopyranose なることを證哟し得たが此等各 Rest の相

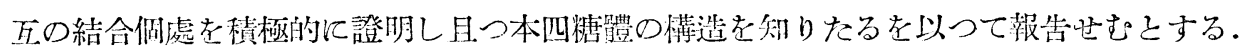

\section{第三章 Glucosereste の結合に關與する炭素の位置}

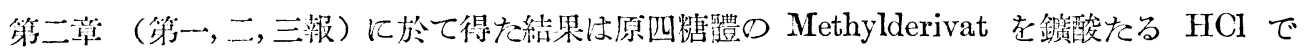
分解して得た Methyl-methylglucosid に就て論じた. 抑も Glucose を始め一般 Zucker 類に於 ては HCl の如き鋌酸を以つて且つ $100^{\circ} \mathrm{C}$ 附近に办熱處理するに於ては O-Brücke の轉位を

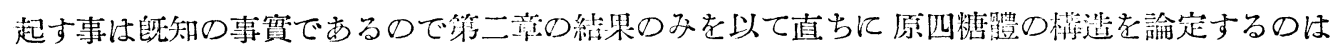

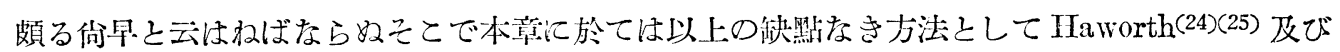
Karrer (23) の主張して居る Acetyl-bromid を以つて $15^{\circ} \mathrm{C}$ 以下の低溫且つ數分間の短時間に 分解を中止せしむる方法を行つた。

Acetyl-bromid による Methyl-derivat の分解(23)(24)(25)

Glucoserest 相互の結合の檢索に於ては Methyl-tetrasaccharid の分解に際し Glucoserest の 絬合を持續して居る Disaccharid か Trisaccharid の Derivat を得るを便とするが就中 Maltose の Derivat を得るならば理想的である。其れ故本分解に於ては該 Maltose-derivat を 得むとした。本 Methyl-derivat を $\mathrm{CH}_{3} \mathrm{CO} \cdot \mathrm{Br}$ で分解すれば次の如く 4 秨の分解成績體が同 一の公筧を以つて生和る䈏である。

以上の分解成續體巾 II を分離の目的にして實驗を進めた, 本分解は Methyl-tetrasaccharid $\left(\mathrm{OCH}_{3} 38 \%\right)$ を $\mathrm{CHCl}_{3}$ 飞溶解して蓪き此れに $\mathrm{CHCl}_{3}$ 溶液となせる $\mathrm{CH}_{3} \mathrm{CO} \cdot \mathrm{Br}$ を㬄加して $15^{\circ} \mathrm{C}$ で $3-5$ 分間分解せしめた。

1. Maltobionsäure の分解

圖に於て明かな如く Methyl-tetrasaccharid が $\mathrm{CH}_{3} \mathrm{CO} \cdot \mathrm{Br}$ で分解を受くるや分解せられた 個處に直に $\mathrm{Br}$ 及び $\mathrm{CH}_{3} \mathrm{CO}$ - 基がそれぞれ大るから斯くして生成した谷分解成續體は frei の OH- 基が無い從つて O-Brücke の轉位が起り得ぬ, 且つ此の分解は完全なる無水の狀態で行 


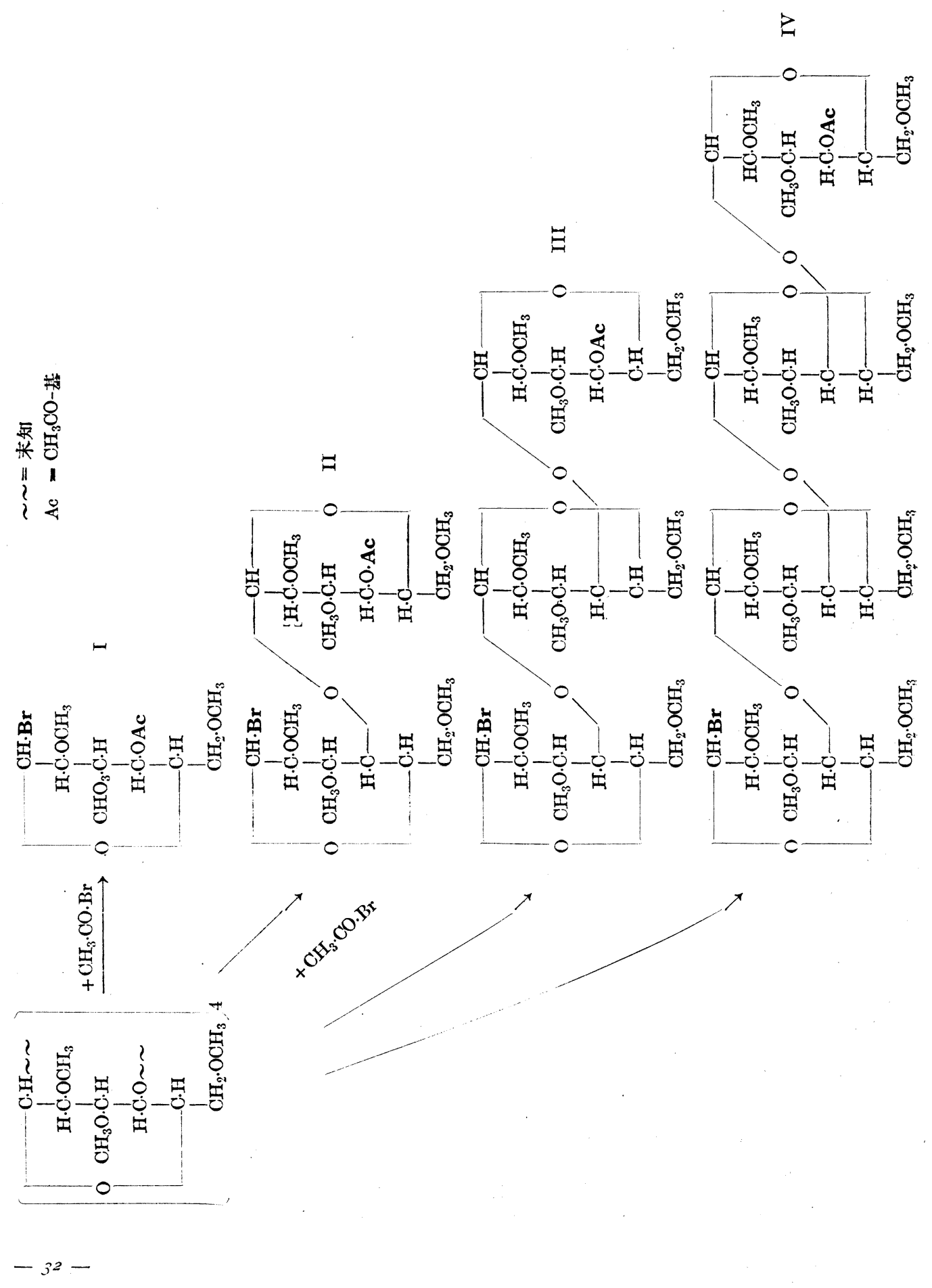




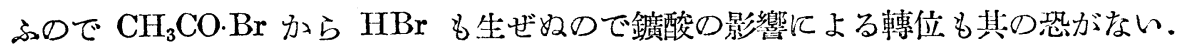

Probe を $\mathrm{CH}_{3} \mathrm{CO} \cdot \mathrm{Br}$ で分解せしむるや過剩の $\mathrm{CH}_{3} \mathrm{CO} \cdot \mathrm{Br}$ を水水を以て分解した副ち反應 $\mathrm{CHCl}_{3}$ 溶液を氷片上に注加し更に $\mathrm{CHCl}_{3}$ 居を氷水で數回洗滌し二次に手早く $\mathrm{NaHCO}_{3}$ 飽和溶 液で振壍して酸を中和除去した, 得た分解成績體は览素 (1)にBr1原子が入つて居るので次 の如く操作して Br を除去した。

$\mathrm{Br}$ の除去

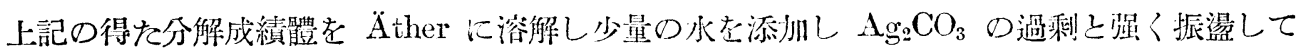
$\mathrm{AgBr}$ として $\mathrm{Br}$ を除去した。

Br-Oxydation

Des-brom-acetyl-methylderivat 在水溶液々なし Benzoesäures-Ba の存在の湖に Br-Oxydation を行つて Aldonsäure-derivat とした.

Octamethyl-maltobionsäure-methylester の分解

上記得た Aldonsäure は Gluconsäure, Maltobionsäure, Trisaccharid の Säure 及び Tetrasaccharid の Säure 等の混合であるから此等を常法によつて完全 Methyl 化した後 Vakuum で 蒸溜して Probe $8 \mathrm{~g}$ 加ら $5.5 \mathrm{~g}$ の溜液を Sirup として得たが更に此の Sirup 在 Hochvakuum で 3 種の分溜液に分つた。

第 1 分溜液 $\left(\mathrm{Kp} .=140^{\circ}-190^{\circ} \mathrm{Bad} / 0.015 \mathrm{~mm}\right) 2 \mathrm{~g}$

第 2 分溜液 $\left(\mathrm{Kp}_{\mathrm{p}}=195^{\circ}-205^{\circ} \mathrm{Bad} / 0.045 \mathrm{~mm}, \mathrm{n}_{\mathrm{i}}^{20}=1.4645, \mathrm{OCH}_{3}\right.$ gef. $\left.=56.56 \%\right) 1.2 \mathrm{~g}$

第 3 分溜液 $\left(\mathrm{Kp} .=205^{\circ}-210^{\circ} \mathrm{Bad} / 0.045 \mathrm{~mm}, \mathrm{n}_{1}^{20}=1.464 \tau, \mathrm{OCH}_{3}\right.$ gef. $\left.=48.7 \%\right) 0.8 \mathrm{~g}$

Octamethyl-maltobionsäure-methylester として $\mathrm{OCH}_{3}$ ber.=57.6\% である上記 3 種の溜液 中第 2，3 丽液を合して更に完全 Methyl 化して Octamethyl-maltobionsäure-methylester $\left([a]_{1}^{20}=+116.1^{\circ}\right.$ in $\mathrm{H}_{2} \mathrm{O}, \mathrm{n}_{\mathrm{b}}^{18}=1.4615, \mathrm{OCH}_{3}$ gef. $=56.3 \%$, ber. $=57.6 \%$. Haworth ${ }^{(24)}:[a]_{\mathrm{D}}^{00}=$ $+116^{\circ}$ in $\mathrm{H}_{2} \mathrm{O}, \mathrm{n}_{\mathrm{D}}^{15}=1.4610, \mathrm{OCH}_{3}$ gef.=57.3\%) $1.1 \mathrm{~g}$ を得た.

2. Octamethyl-maltobionsäure-methylester $の$ 加水分解

本 Methylester V \& frei の OH一基が 1 個も䇛いから加水分解によつて二つの Glucosereste を得れば A-rest に 1 個の $\mathrm{OH}$ - 基が frei となり且つ岑䒺(1)か ら $\mathrm{CH}_{3} \mathrm{OH}$ が外れて Tetramethylgluconsäure となり B-rest はVII Tetramethylglucopyranose となる. 前者A-rest 中の新生O H-基の位置を決定すれば其れが師ち他 Rest との結合の位置となる其の沈定法はVI Gluconsäurelacton が $\delta$-Form か $\gamma$-Form かを決定すればよん. 前间同樣に Phenylhydrazid

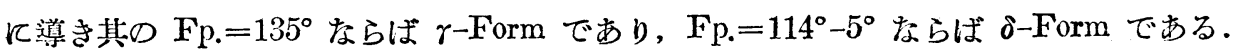

本 Methylester V $0.8 \mathrm{~g}$ を $\mathrm{HCI}$ で加水分解した後 $\mathrm{HCl}$ を $\mathrm{BaCO}_{3}$ で除去すれば A-rest は Ba-salz として存在するので B-rest t Aceton t以つて浸出除去した後 HCl で Ba-salz 


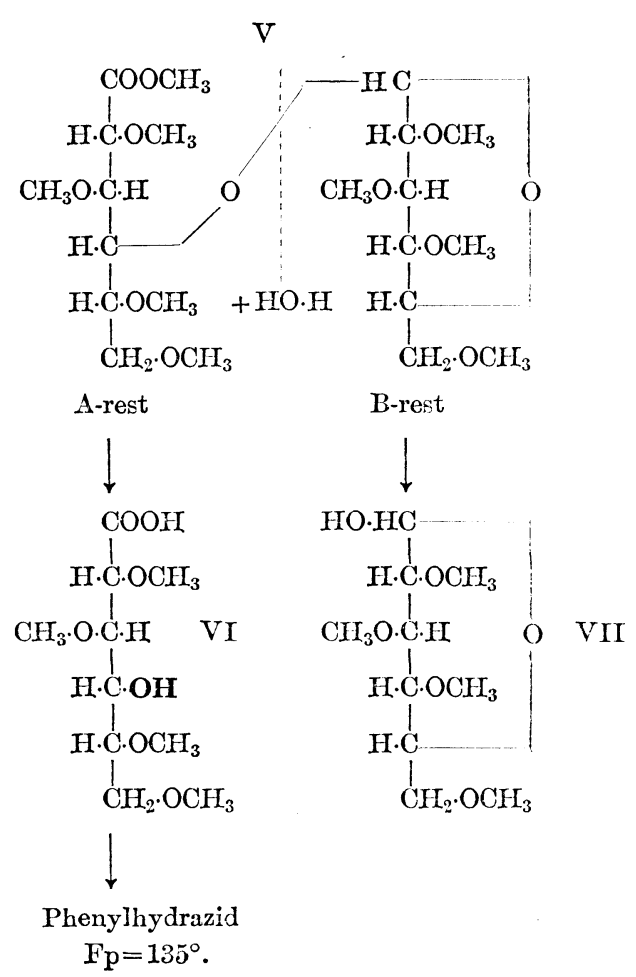

を分解して Tetramethylgluconsäure を Sirup として $0.36 \mathrm{~g}$ を得たので更に Phenylhydrazid として Fp.=135 に薄き得た B-rest のAceton 浸出液を蒸溜してAceton 在除夫し $(2: 3: 4: 6)$ Tetramethylglucopyranose Fp. $=89^{\circ}$ を $0.35 \mathrm{~g}$ 得たTetramethylglucose として Literaturにあ るもの Haworth(26): (2:3:4:6)-Tetramethyl glucopyranose Fp. $=89^{\circ}$ と一致する此れ行反し $\tau(2: 3: 5: 6)^{(27)-T e t r a m e t h y l-g l u c o f u r a n o s e}$ はSirupである。 以上の賽驗から A-Rest $の(4)$ そB-rest $の(1)$ とが結合して居つたことが明かとなつた。

符三章の結論

原四糖體に於て Glucoserest 相互の結合が 假りに（1:5)であり且つFuranose であると するならば A-rest からは Phenylhydrazid と

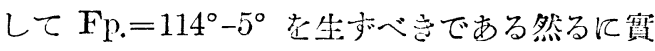
驗の結果は Fp. 1350であるので結合は（1↔4) であり同時に Pyranose であるこょになつた 斯くして第二章の絬果と全く一致すると到つた。

\section{結論}

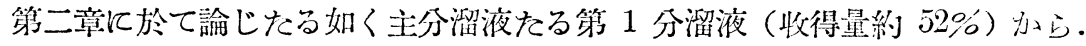

1. Glucosereste 中に $(2: 3: 6)$ の位置の $\mathrm{OH}$-基が遊離して居るもの相當多量あるここ。 第 2 分溜液(收得量約 $23 \%$ ) 汃 .

2. Glucosereste 中に $(2: 3)$ の位置の $\mathrm{OH}$-基が遊離して居るものもあるてょ。

3. 各 Glucoserest は Pyranose 型なること.

4. 遊離 Aldehyd-基なきてと。

第三章に諭ぜる如く 。

5. Glucose-rest 相互の結合の一型として $1 \leftrightarrow 4$ があるとと.

上記第 2 に記载せる如く(2:3)-Dimethyl-derivat を得るに係はらす㖩も Methyl一化せら れ易き（6）の位置に $\mathrm{OCH}_{3}$-基を有する Derivat を得られざる事賽を考ふるならば恐！(6) の位置の $\mathrm{OH}$-基は結合に消費せられて居りしならむ節ち 
6. Glucoserest 相互の結合の一型に $1 \leftrightarrow 6$ もあるらしきとと.

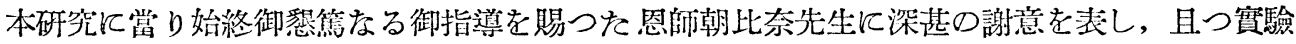
の協力を得た渡部忠雄君站に分析を煩はした宮澤學士に讙んで感謝する。

\section{實 驗 の 部}

\section{$\mathrm{CH}_{3} \mathrm{CO}-\mathrm{Br} \mathbf{r}^{(23)(24)(25)}$ による Tetrasaccharid の分解.}

\section{Maltobionsäure の分解.}

Methyl-tetrasaccharid $\left(\mathrm{OCH}_{3} 38 \%\right) 8 \mathrm{~g}$ を無水 $\mathrm{CHCl}_{3} 250 \mathrm{cc}$ に溶解し犆き此れに純粹なる $\mathrm{CH}_{3} \mathrm{CO} \cdot \mathrm{Br}$ $25 \mathrm{~g}$ を同じく $\mathrm{CHCl}_{3} 250 \mathrm{cc}$ に溶解したものを加へて $15^{\circ} \mathrm{C}$ 以下に保ちつつ 3-5 分間分解せしめた次に反 應液を氷の細片上に注加して過剩の $\mathrm{CH}_{3} \mathrm{CO} \cdot \mathrm{Br}$ を分解した後 $\mathrm{CHCl}_{3}$ 曆を分液漏斗に移し氷水を以つて數 回手早く洗浟し最後に $\mathrm{NaHCO}_{3}$-飽和水溶液で 2,3 包强く振温して $\mathrm{CHICl}_{3}$ 溶液を中和して酸を除去した，

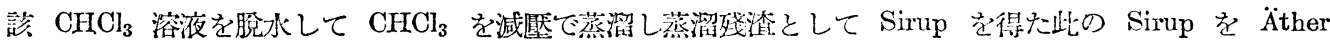
$100 \mathrm{cc}$ に溶解し少量の $\mathrm{H}_{2} \mathrm{O}$ を添加した後 $\mathrm{A}_{2} \mathrm{CO}_{3}$ の稍々過剩 $10 \mathrm{~g}$ を加一て振温器上で 12 時閒振温して

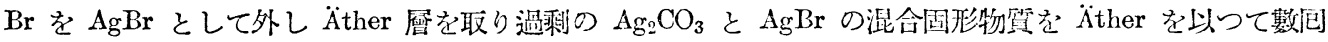

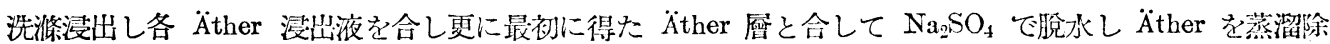

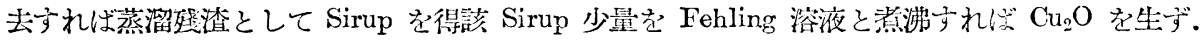

Methyl-acetyl-化合體の $\mathrm{Br}$ による酸化:(23) 上記 $\mathrm{Br}$ を除去した Methyl-acetyl-化合體を $\mathrm{H}_{2} \mathrm{O} 400 \mathrm{cc}$ に溶解し Ba-benzoat $16 \mathrm{~g}$ 丈び Br $0.8 \mathrm{cc}$ を添加して窒溫に 24 洔間反應を續行せしめた後, 流通空氣を 以つて過剩の $\mathrm{Br}$ を追ひ出し析出した $\mathrm{C}_{6} \mathrm{H}_{5} \mathrm{COOH}$ を源別する然る時は生成した Sïure は Ba-salz として

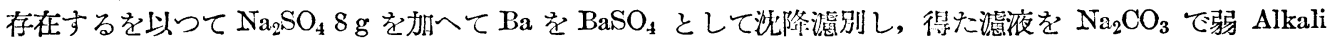

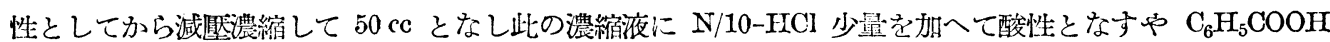
が析出するので此れを absaugen し，得た㵽夜を再び $\mathrm{Na}_{2} \mathrm{CO}_{3}$ で弱 Alkali 性となし前包同樣蒸發して $20 \mathrm{cc}$ となし $\mathrm{HCl}$ で酸性となし殘存して居る $\mathrm{C}_{6} \mathrm{H}_{5} \mathrm{COOH}$ を可及的完全に析出せしめ absaugen して濾液を得た

Methyl-acetyl-aldonsäure の Methyl-化及び Methylester-化.

上記に得た濾液を Aceton $20 \mathrm{cc}$ に溶解し Dimethylsulfat $25 \mathrm{cc}$ と $30 \% \mathrm{NaOH} 67 \mathrm{cc}$ とを以つて 3 䣎

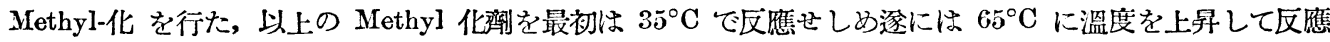
を促進せしめた此の反應夜を水で $0^{\circ} \mathrm{C}$ まで冷却し更に水片を加へて $0^{\circ} \mathrm{C}$ に保ちつつ Kongorot で $5 \mathrm{~N}$ $\mathrm{H}_{2} \mathrm{SO}_{4}$ を加へて弱酸性とした後 $\mathrm{CHCl}_{3} 1200 \mathrm{cc}$ を以つて數回浸出した. 殘留した母液曆を $\mathrm{NaOH}$ て弱 Alkali 性となし $60^{\circ} \mathrm{C}$ 以下で蒸發乾涸に到らしめ該乾涸物質を $90 \% \mathrm{C}_{2} \mathrm{HI}_{5} \mathrm{OH}$ で蒸沰しつつ核出して得た 浸出 $\mathrm{C}_{2} \mathrm{H}_{5} \mathrm{OH}$ 溶液を減朢蒸溜して $\mathrm{C}_{2} \mathrm{H}_{5} \mathrm{OH}$ を除去すれば目的物たる Sïure は Na-salz として析出して 來る此の Na-salz を水に溶解して先きに $\mathrm{CHCl}_{3}$ 浸出によつて得た物質と共に再 Methyl-化を行つた. 次 に前回同樣に $\mathrm{H}_{2} \mathrm{SO}_{4}$ て酸性として $\mathrm{CHCl}_{3}$ で浸出し此の $\mathrm{CHCl}_{3}$ 湜出液を蒸溜して $\mathrm{CHCl}_{3}$ を除去して Sirup を得た此の Sirup を更に $\mathrm{CH}_{3} \mathrm{~J} 10 \mathrm{cc}$ に溶解し $\mathrm{Ag}_{2} \mathrm{O} 5 \mathrm{~g}$ を以つて Methyl-化二回行つた後 $\mathrm{Ag}_{2} \mathrm{O}$ $\mathrm{CH}_{3} \mathrm{~J}$ を除去して Sirup $6 \mathrm{~g}$ を得更に該 Sirup を Hochvakuum で分溜して次の 3 種の分溜液と蒸溜残 渣とを得た。

第 1 分溜液 $\mathrm{Kp} .=140^{\circ}-90^{\circ}$ B.u $/ 0.15 \mathrm{~mm}$

第 2 分溜液 $\mathrm{Kp} .=19 \overline{5}^{\circ}-205^{\circ \mathrm{Bad}} / 0.045 \mathrm{~mm}, \mathrm{n}_{\mathrm{D}}^{20}=1.464 \bar{\jmath}$

第 3 分溜液 $\mathrm{Kp} .=205^{\circ}-215^{\circ \mathrm{Bad}} / 0.045 \mathrm{~mm}, \mathrm{n}_{b}^{20}=1.4647$ 蒸溜殘椬

\begin{tabular}{|c|c|c|}
\hline & $\mathrm{OCH}_{3}$ & 得量 \\
\hline $2.0 \mathrm{~g}$ & 、 & $36.4 \%$ \\
\hline $1.2 \mathrm{~g}$ & $56.56 \%$ & $21.8 \%$ \\
\hline $0.8 \mathrm{~g}$ & $48.7 \%$ & $14.5 \%$ \\
\hline $15 \mathrm{~g}$ & & \\
\hline $5.5 \mathrm{~g}$ & & \\
\hline
\end{tabular}


Octamethyl-maltobionsäure-methylester : $\mathrm{OCH}_{3}$ ber.=57.6\% であるから第 2 分溜液は本 Methylester ならむも第 3 分溜液は其の不完全 Methyl 化物質と見做し兩分溜夜を合し $1.1 \mathrm{~g}$ を $\mathrm{CH}_{3} \mathrm{~J} 15 \mathrm{cc}$, $\mathrm{Ag}_{2} \mathrm{O} 3 \mathrm{~g}$ を以つて3司 Methyl-化し更に分溜して Octamethyl-maltobionsïure-methylester $\left(\mathrm{n}_{\mathrm{D}}^{18}=1.4615\right.$, $\mathrm{OCH}_{3}$ gef. $=56.3 \%,[\alpha]_{\mathrm{b}}^{20}=+116 .{ }^{\circ} 1$ in $\mathrm{H}_{2} \mathrm{O}$ Haworth $: \mathrm{n}_{\mathrm{D}}^{18}=1.4620,[\alpha]_{\mathrm{b}}^{25}=+116^{\circ}$ in $\left.\mathrm{H}_{2} \mathrm{O}\right) 0.85 \mathrm{~g}$ を得た.

2. Octamethyl- maltobionsäure-methylester の $\mathrm{HCl}$ による加水分解.

上記得た Octamethyl-maltobionsüure-methylester $0.85 \mathrm{~g}$ を $5 \%-\mathrm{HCl}$ 水溶液 $14 \mathrm{cc}$ に溶解し水浴中て $95^{\circ} \mathrm{C}$ に加熱加水分解を行ら此の間時々反應液の $\alpha_{\mathrm{D}}$ を測定し其の分解の完了を知つた区應開始 $\alpha_{\mathrm{D}}=+6.5^{\circ}, 3$ 時間後 $+3.35^{\circ}: 5$ 時間後 $+3,20^{\circ}, 7$ 時聞後 $+3.20^{\circ}$ ，此の點に於て分解を中止して $\mathrm{BaCO}_{3}$ を加へて $\mathrm{HCl}$ を 中和した後過剩の $\mathrm{BaCO}_{3}$ を㴓別し得た溞液を $\mathrm{Ba}(\mathrm{OH})_{2}$ で弱 Alkali 性として $37^{\circ} \mathrm{C}$ 一夜放置した。

$d$-(2:3:4:6)-Tetramethylglucopyranose とd-(2:3:5:6)-Tetramethyl- $\gamma$-gluconsäurelacton Łの 分離.

上記 $\mathrm{Ba}(\mathrm{OH})_{2}$ Alkali 性滤液に $\mathrm{CO}_{2}$ 瓦斯を通じて過剩の $\mathrm{Ba}$ を沈降濾別した後得た滤液を娍壓蒸溜し こ乾涸に到る此の乾涸物質を Aceton 少量を加へて浸出し不溶性物質と可溶性物質とに分ける.Aceton 浸 出液を蒸溜して Aceton を除去し得た蒸溜殘渣を更に無水 Aceton を以つて浸出して無機物質を分離除去し 得た Aceton 溶液を蒸溜して蒸溜殘渣として最後に Sirup 0.35 g (得量 $82.4 \%$ ) を得た次に绕 Sirup を不 油エーテルから針狀結晶として Fp. $=87^{\circ}-9^{\circ}\left(\right.$ Haworth $\left.:(26) \mathrm{Fp} .=89^{\circ}\right)$ の d-(2:3:4:6)-Tetramethylglucopyranose を得た。

元素分析： $\mathrm{C}_{10} \mathrm{H}_{20} \mathrm{O}_{6}=236$.

$$
\begin{array}{rlrl}
\text { Sbst. }=3.955 \mathrm{mg} \quad \mathrm{CO}_{2} & =7.424 \mathrm{mg} & \mathrm{H}_{2} \mathrm{O} & =2.996 \mathrm{mg} \\
\text { C gef. } & =51.19 \% & \mathrm{H} \text { gef. } & =8.48 \% \\
\text { ber. } & =\mathbf{5 0 . 8 5 \%} & \text { ber. } & =8.48 \%
\end{array}
$$

Aceton 不溶性物質を少量の水に溶解した後 N/10-HCJ な加へて鑛酸酸性となし減監蒸溜して乾涸する に到る該乾涸物質を無水 $\ddot{A t h e r ~ て ゙ ~} 5$ 包浸出し各浸出液を合し脫水した後 Äther を蒸溜除去し蒸溜殘渣 として Sirup $0.36 \mathrm{~g}$ (得量 66\%) の Tetramethyl-gluconsïurelacton $\left(\mathrm{OCH}_{3}\right.$ gef. $=49.2 \%$, ber. $=53 \%$ )を 得たが更に此の Sirup $0.3 \mathrm{~g}$ を Hochvakuum で分溜してSirup ( $\mathrm{Kp}=95^{\circ}-100^{\circ \mathrm{Bad}} / 0.004 \mathrm{~mm}, \mathrm{n}_{\mathrm{b}}^{18}=1.4502$, $\mathrm{OCH}_{3}$ gef. $=52.9 \%$, ber. $\left.=53 \%\right) 0.1 \mathrm{~g}$ を得た，更に該 Sirup き Phenylhydrazin と水浴中で $100^{\circ} \mathrm{C}$ に加

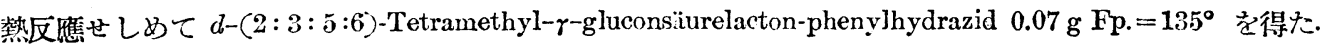

元素分析： $\mathrm{C}_{16} \mathrm{H}_{26} \mathrm{O}_{6} \mathrm{~N}_{2}=342$.

$$
\begin{aligned}
\text { Sbst. }=3.640 \mathrm{mg} \quad \mathrm{CO}_{2} & =7.440 \mathrm{mg} \quad \mathrm{H}_{2} \mathrm{O}=2.540 \mathrm{mg} \\
\mathrm{C} \text { gef. } & =55.74 \% \quad \mathrm{H} \text { gef. }=7.81 \% \\
\text { ber. } & =56.14 \% \quad \text { ber. }=7.60 \% \\
\text { Sbst. } & =3.460 \mathrm{mg} \quad \therefore \text { vol. }=0.241 \mathrm{cc}\left(15^{\circ}, 760 \mathrm{~mm}\right) \quad \therefore \text { gef. }=8.26 \% \quad \text { ber. }=8.19 \%
\end{aligned}
$$

(23) Karrer: Helv. 1921 264, 678.

(24) Haworth \& Percival: Soc. 19311342.

(25) Haworth, Hirst \& Thomas: Soc. 1931 824.

(26) Haworth \& Leitch: Soc. 19221921.

(27) Irvine: Soc. $1915 \mathbf{5 2 4}$. 